$\overline{\text { Original }}$

\title{
Identification of Principal Constituents in Enzymatically Hydrolyzed Coix Extract
}

\author{
(Received May 11, 2001) \\ Naoki Sugimoto ${ }^{\dagger}$, Junko Fukuda, Kosuke Takatori, Takashi Yamada and Tamio Maitani \\ (National Institute of Health Sciences: 1-18-1, Kamiyoga, Setagaya-ku, \\ Tokyo 158-8501, Japan; ${ }^{\dagger}$ Corresponding author)

\begin{abstract}
The structural elucidation of the main constituents in enzymatically hydrolyzed coix extract, a natural food preservative, was carried out. After peracetylation, five compounds, namely peracetylated forms of glucose, maltose, maltotriose, maltotetraose, and maltopentaose were isolated. The structures were determined by PFG HMQC and HMBC experiments. In addition, by using HPLC with an RI detector, the main components of this coix extract were identified as a mixture of oligosaccharides having one to seven glucose units coupled through $\alpha-(1 \rightarrow 4)$ linkages. Since this extract showed no antimicrobial activity, its preservative effect may be caused by its covering of the food surface, thereby blocking contact with air.
\end{abstract}

Key words: enzymatically hydrolyzed coix extract; Coix lachryma-jobi L. var. ma-yuen STAPF; oligosaccharide; natural preservative; antimicrobial activity

\section{Introduction}

Many kinds of food additives are used in the manufacture of modern processed foods, with preservatives being the most important type. Since these items have bioactivities, in that they suppress the growth of microorganisms in food, only preservatives that have been confirmed as having no harmful effects in humans can be used in foods. Nevertheless, consumers are concerned about the use of preservatives in foods, and often reject foods with artificial preservatives, as they are anxious about adverse effects, especially following reports in the mass media. Interest in the use of natural preservatives is increasing in Japan due to this consumer pressure.

In the List of Existing Food Additives in Japan ${ }^{1)}, 10$ natural preservatives are listed including enzymatically hydrolyzed coix extract. It is described as "a substance obtained by enzymatically hydrolyzing the seeds of Job's Tears (Coix lachryma-jobi L. var. mayuen)". However, the effective and main components are not revealed in the list ${ }^{1)}$.

In this paper, in order to establish specifications for enzymatically hydrolyzed coix extract, identification of the structures of the constituents was carried out by NMR after the main constituents had been acetylated. Quantification was performed by HPLC.

\section{Materials and Methods}

\section{Sample and standard compounds}

The sample of enzymatically hydrolyzed coix extract was obtained through the Japan Food Additives Association. Glucose (Wako Pure Chemical Industries Co.,
Ltd.), $\alpha$-D(+)-glucose pentaacetate (Sigma Co., Ltd.), $\beta$ $\mathrm{D}(+)$-glucose pentaacetate (Sigma), $\beta$-D-maltose monohydrate (Wako), maltotriose (Sigma), maltotetraose (Sigma), and maltopentaose (Katayama Chemical Industries Co., Ltd.) were used as standards for NMR and HPLC analyses. Silica gel 60 F254 $(20 \mathrm{~cm} \times 20 \mathrm{~cm}$, Art. 1.05715 (Merck Co., Ltd.)) and RP-18WF254s (10 cm X $10 \mathrm{~cm}$, Art. 13124 (Merck)) were used for TLC. Silica gel 60 (70-230 mesh Art. 1.07734 (Merck)) and Diaion HP20 (Mitsubishi Chem. Ind. Co., Ltd.) were used for open column chromatography.

HPLC analysis of enzymatically hydrolyzed coix extract

HPLC was performed with a high-performance liquid chromatography system (Shimadzu LC-6A) using the following conditions: condition A (for oligosaccharide analysis): column, Capcellpak $\mathrm{NH}_{2}$ (4.6 mm i.d. $\times 250$ $\mathrm{mm}$ ) (Shiseido Co., Ltd.); mobile phase, $80 \%$ acetonitrile $\left(\mathrm{CH}_{3} \mathrm{CN}\right)$; flow rate, $0.8 \mathrm{~mL} / \mathrm{min}$; detection, $\mathrm{RI}$; column temperature, $40^{\circ} \mathrm{C}$; condition $\mathrm{B}$ (for polysaccharide analysis): column, Daisopak SP-120-5-ODS-BP (4.6 mm i.d. $\times$ $150 \mathrm{~mm}$ ) (Daiso Co., Ltd.); mobile phase, water $\left(\mathrm{H}_{2} \mathrm{O}\right)$; flow rate, $0.7 \mathrm{~mL} / \mathrm{min}$; detection, $\mathrm{RI}$; column temperature, $40^{\circ} \mathrm{C}$. The quantities of oligosaccharides were determined by means of the absolute calibration method by HPLC under condition A.

\section{Spectroscopic analyses}

NMR spectra were recorded on a JEOL JNM-alpha $(500 \mathrm{MHz})$ with chloroform- $d\left(\mathrm{CDCl}_{3}\right)$ as the solvent. Spectra were referenced internally to tetramethysilane (TMS) for ${ }^{1} \mathrm{H}-\mathrm{NMR}$ and to the solvent for ${ }^{13} \mathrm{C}-\mathrm{NMR}$. Assignments of the proton and carbon signals of all 


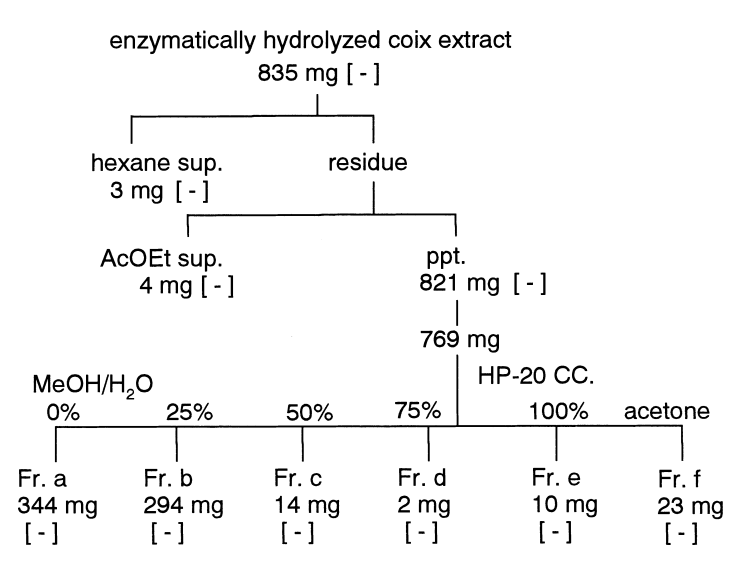

Fig. 1. Antimicrobial activities and fractionation of enzymatically hydrolyzed coix extract $[-]=$ negative, $[+]=$ positive: antimicrobial activity against $E$. coli, $S$. cerevisiae, and $A$. niger

isolated compounds were confirmed by pulse field gradient (PFG) heteronuclear multiple quantum coherence (HMQC) and PFG heteronuclear multiple bond connectivity (HMBC) experiments.

\section{Assay for antimicrobial activity}

Escherichia coli ATCC 8739, Saccharomyces cerevisiae IFO 1952, and Aspergillus niger TSY 0517 were used to test for antimicrobial activities of the extract. Each cell suspension was prepared using fresh microbes at least 3 times. Finally, E. coli and S. cerevisiae were diluted to $0.75 \%$ sodium chloride $(\mathrm{NaCl})$ solution at $10^{6} \mathrm{CFU} / \mathrm{mL}$, and $A$. niger was prepared by dilution with $0.1 \%$ Tween 80 (Katayama)/0.75\% NaCl solution. Twenty-five $\mathrm{mL}$ of medium (standard agar medium (Nissui) for $E$. coli, potato dextrose agar medium (Nissui) for $S$. cerevisiae and $A$. niger) was poured into a plastic plate (diameter: 9 $\mathrm{cm})$. The test samples were soluble in methanol $(\mathrm{MeOH})-$ dimethyl sulfoxide (DMSO) $-\mathrm{H}_{2} \mathrm{O}=4: 4: 1^{2}$. The sample $(100 \mathrm{mg} / \mathrm{mL}, 20 \mu \mathrm{L})$ was added to a paper disc $(\phi 8 \mathrm{~mm}$, Advantec), and the solvent was removed at room temperature. An aliquot of $100 \mu \mathrm{L}$ of each microbial suspension was inoculated onto the surface of the agar medium, and the prepared paper disc was placed on the medium. After incubation at $36^{\circ} \mathrm{C}$ for 48 hours, the antimicrobial activity was obtained by measuring the radius of the inhibitory zone (paper disc method) ${ }^{3}$.

\section{Fractionation of enzymatically hydrolyzed coix extract}

The solvent of the enzymatically hydrolyzed coix extract was removed in vacuo, and the residue (835 $\mathrm{mg}$ ) was extracted with hexane and ethyl acetate (AcOEt), successively, affording a hexane-soluble part (3 $\mathrm{mg})$, an AcOEt-soluble part $(4 \mathrm{mg})$ and a precipitate $(821 \mathrm{mg}$ ) soluble in neither hexane nor AcOEt. The precipitate was successively chromatographed on Diaion HP-20 with $\mathrm{H}_{2} \mathrm{O}, 25 \% \mathrm{MeOH}, 50 \% \mathrm{MeOH}, 75 \% \mathrm{MeOH}, \mathrm{MeOH}$, and acetone with monitoring by TLC, and the eluates were concentrated in vacuo, affording six fractions: frs. a, b, c, d, e, and f, respectively (Fig. 1).

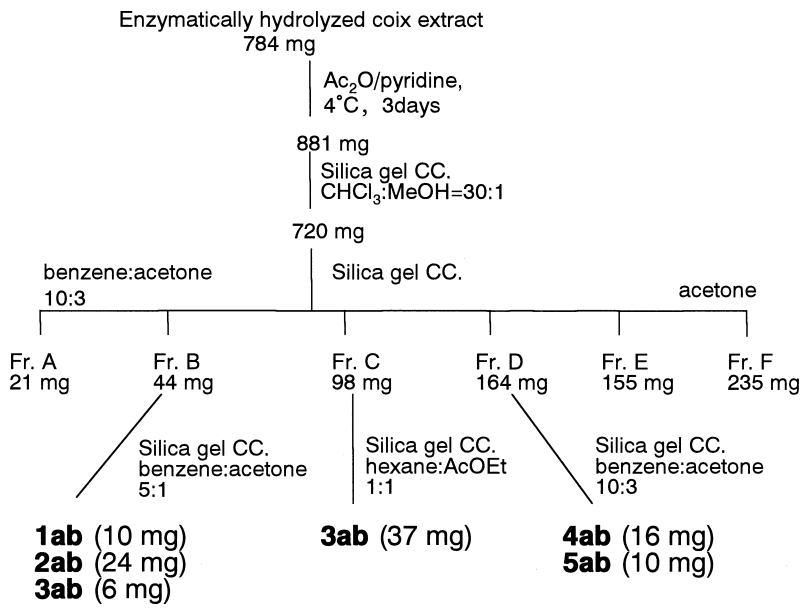

Fig. 2. Fractionation of acetylated enzymatically hydrolyzed coix extract

Isolation of peracetylated enzymatically hydrolyzed coix extract

The solvent of the enzymatically hydrolyzed coix extract was removed in vacuo, to afford a residue (784 $\mathrm{mg})$. Acetylation of the residue $(784 \mathrm{mg})$ in pyridine (3 $\mathrm{mL})$ and acetic anhydride $\left(\mathrm{Ac}_{2} \mathrm{O}\right)(2 \mathrm{~mL})$ was carried out at $4^{\circ} \mathrm{C}$ for 3 days. The reaction mixture was added to AcOEt (ca. $20 \mathrm{~mL}$ ) and the organic layer was washed with $5 \%$ hydrochloric acid $(\mathrm{HCl})$ and $\mathrm{H}_{2} \mathrm{O}, 2$ times each, then the solvent was removed in vacuo. The residue (881 mg) was fractionated repeatedly by silica gel column chromatography using $\mathrm{CHCl}_{3}-\mathrm{MeOH}(30: 1)$ and benzene-acetone $(10: 3)$, to afford Frs. A (21 mg), B (44 mg), C (98 mg), D (164 mg), E (155 mg), and F (235 $\mathrm{mg})$. Subsequently, $\mathbf{1} \mathbf{a b}(10 \mathrm{mg}), \mathbf{2 a b}(24 \mathrm{mg})$ and $\mathbf{3 a b}(6$ $\mathrm{mg}$ ) from Fr. B, 3ab (37 mg) from Fr. C, and $4 \mathbf{a b}(16 \mathrm{mg})$ and $5 \mathbf{a b}(10 \mathrm{mg})$ from Fr. D, were isolated by silica gel column chromatography using benzene-acetone and hexane-AcOEt solvent systems.

$\alpha$-Isomerization of acetylated oligosaccharide $\alpha / \beta$ isomer (reaction method)

$\alpha$-Isomerization of isolated $\mathbf{2 a b}(10 \mathrm{mg})$ in $\mathrm{Ac}_{2} \mathrm{O}(2 \mathrm{~mL})$ over zinc chloride $\left(\mathrm{ZnCl}_{2}\right)(2 \mathrm{mg})$ as a catalyst was carried out at $60^{\circ} \mathrm{C}$ for 3 hours. The reaction mixture was added to AcOEt (ca. $20 \mathrm{~mL}$ ) and the organic layer was washed with water 3 times, then the solvent was removed in vacuo. The residue was purified by silica gel column chromatography using benzene-acetone (10:3), and $\mathbf{2 a}(8 \mathrm{mg})$ was obtained as a colorless powder. By using the same procedure, $3 \mathbf{a}, \mathbf{4 a}$, and $\mathbf{5 a}$ were obtained from $3 \mathbf{a b}, 4 \mathbf{a b}$, and $5 \mathrm{ab}$, respectively.

\section{Preparation of standard acetylated oligosaccharide (reac- tion method)}

Acetylation of $\beta$-D-maltose monohydrate $(400 \mathrm{mg})$ in pyridine $(3 \mathrm{~mL})$ and $\mathrm{Ac}_{2} \mathrm{O}(2 \mathrm{~mL})$ was carried out at $4{ }^{\circ} \mathrm{C}$ for 4 hours. The reaction mixture was added to AcOEt (ca. $20 \mathrm{~mL}$ ), the organic layer was washed with $5 \% \mathrm{HCl}$ and water, 2 times each, and the solvent was removed in vacuo. The residue $(584 \mathrm{mg})$ was purified by silica gel 


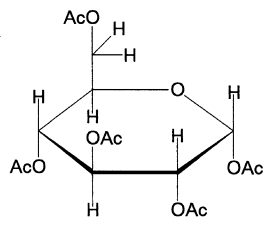

1a

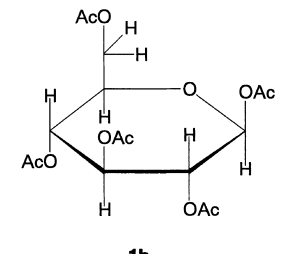

1b

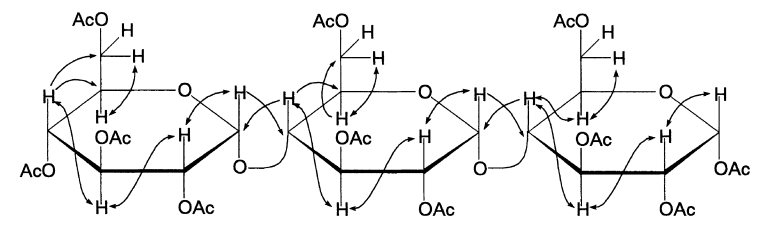

3a
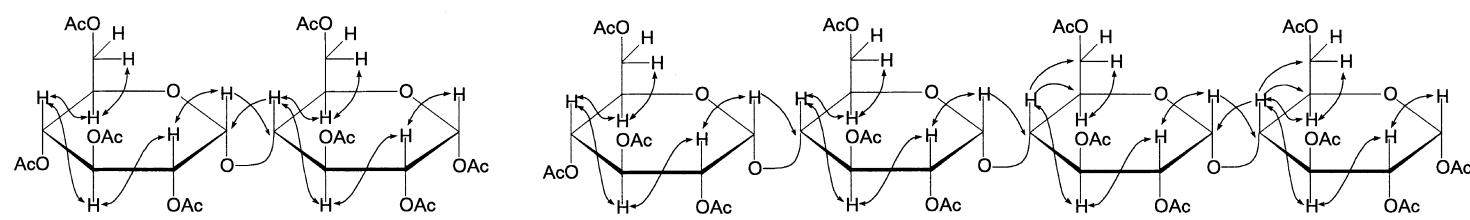

2a
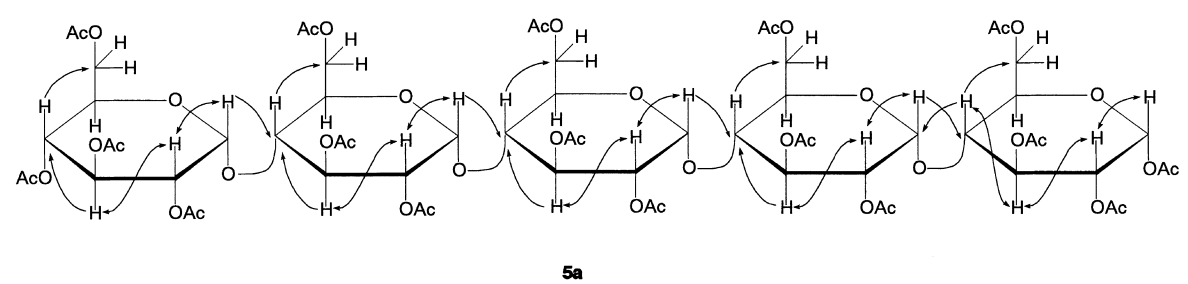

$\rightarrow \quad \mathrm{HMBC}$

$\longleftrightarrow \mathrm{H}-\mathrm{H}$ COSY

Fig. 3. Structures of peracetylated oligosaccharides

Table 1. ${ }^{13} \mathrm{C}-\mathrm{NMR}$ Chemical Shifts $\left(\delta\right.$, ppm, in $\left.\mathrm{CDCl}_{3}\right)$ of Acetylated Oligosaccharides

\begin{tabular}{|c|c|c|c|c|c|c|}
\hline & 1a & $1 b$ & $2 a$ & $3 a$ & $4 a$ & $5 a$ \\
\hline 1 & 89.1 & 91.7 & 88.8 & 88.8 & 88.8 & 88.9 \\
\hline 2 & 69.2 & 70.2 & 69.7 & 69.7 & 69.7 & 69.8 \\
\hline 3 & 69.8 & 72.7 & 72.3 & 72.1 & 72.2 & 72.2 \\
\hline 4 & 67.9 & 67.7 & 72.3 & 73.3 & 73.3 & 73.3 \\
\hline 5 & 69.8 & 72.7 & 70.1 & 70.2 & 69.1 & 69.1 \\
\hline 6 & 61.5 & 61.4 & 62.4 & 62.5 & 62.3 & 62.3 \\
\hline $1^{\prime}$ & & & 95.8 & 95.9 & 95.9 & 95.9 \\
\hline $2^{\prime}$ & & & 70.0 & 70.4 & 70.4 & 70.5 \\
\hline $3^{\prime}$ & & & 69.3 & 71.7 & 71.5 & 71.7 \\
\hline $4^{\prime}$ & & & 67.9 & 72.3 & 72.3 & 72.4 \\
\hline $5^{\prime}$ & & & 68.6 & 69.0 & 69.0 & 69.0 \\
\hline $6^{\prime}$ & & & 61.4 & 62.1 & 62.2 & 62.2 \\
\hline $1^{\prime \prime}$ & & & & 95.6 & 95.8 & 95.8 \\
\hline $2^{\prime \prime}$ & & & & 70.1 & 70.4 & 70.5 \\
\hline $3^{\prime \prime}$ & & & & 69.3 & 71.7 & 71.6 \\
\hline $4^{\prime \prime}$ & & & & 67.9 & 73.4 & 73.3 \\
\hline $5^{\prime \prime}$ & & & & 68.4 & 70.0 & 68.9 \\
\hline $6^{\prime \prime}$ & & & & 61.3 & 62.6 & 62.4 \\
\hline $1^{\prime \prime \prime}$ & & & & & 95.6 & 95.8 \\
\hline $2^{\prime \prime \prime}$ & & & & & 70.1 & 70.5 \\
\hline $3^{\prime \prime \prime}$ & & & & & 69.3 & 71.6 \\
\hline $4^{\prime \prime \prime}$ & & & & & 67.9 & 73.4 \\
\hline $5^{\prime \prime \prime}$ & & & & & 68.4 & 70.2 \\
\hline $6^{\prime \prime \prime}$ & & & & & 61.3 & 62.5 \\
\hline $1^{\prime \prime \prime \prime}$ & & & & & & 95.6 \\
\hline $2^{\prime \prime \prime \prime}$ & & & & & & 70.0 \\
\hline $3^{\prime \prime \prime \prime}$ & & & & & & 69.3 \\
\hline $4^{\prime \prime \prime \prime}$ & & & & & & 67.9 \\
\hline $5^{\prime \prime \prime \prime}$ & & & & & & 68.4 \\
\hline $6^{\prime \prime \prime \prime}$ & & & & & & 61.4 \\
\hline $\mathrm{CH}_{3}$ & $20.4-20.8$ & $20.5-20.8$ & $20.3-20.9$ & $20.3-20.9$ & $20.4-21.0$ & $20.4-21.0$ \\
\hline $\mathrm{C}=\mathrm{O}$ & $168.7-170.6$ & $168.9-170.5$ & $168.8-170.5$ & $168.7-170.5$ & $168.9-170.5$ & $168.9-170.6$ \\
\hline
\end{tabular}




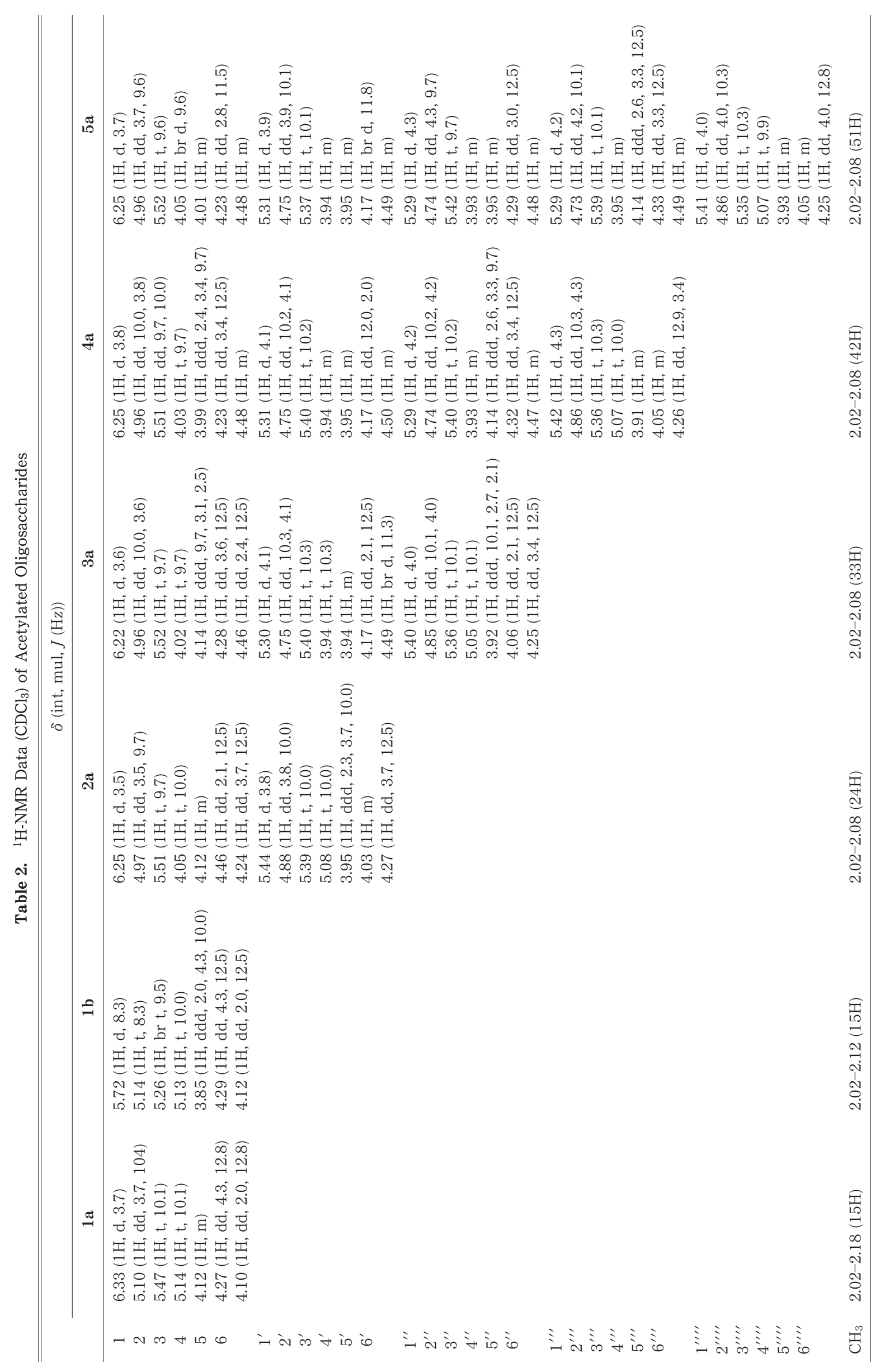


column chromatography using hexane-AcOEt $(1: 1)$, and $\beta$-maltose octaacetate ( $2 \mathbf{b}, 320 \mathrm{mg}$, yield: $40 \%$ ) was obtained as a colorless powder. $\alpha$-Isomerization of $2 \mathbf{b}$ (40 mg) in acetone (2 mL) over $\mathrm{ZnCl}_{2}(2 \mathrm{mg})$ as a catalyst was carried out at $65^{\circ} \mathrm{C}$ for 5 hours. The reaction mixture was added to AcOEt (ca. $20 \mathrm{~mL}$ ), the organic layer was washed with water 3 times, and the solvent was removed in vacuo. The residue was purified by silica gel column chromatography using hexane-AcOEt (1:1), and $\mathbf{2 a}(32 \mathrm{mg}$, yield: $80 \%)$ was obtained as a colorless powder. By using the same procedure, $\mathbf{3 a}, \mathbf{4 a}$, and $5 \mathbf{a}$ were obtained from maltotriose (Sigma), maltotetraose (Sigma), and maltopentaose (Katayama).

\section{Results and Discussion}

\section{Antimicrobial activity}

Antimicrobial activities against E. coil, S. cerevisiae, and $A$. niger were measured by using the paper disc test (Halo test), but enzymatically hydrolyzed coix extract showed no antimicrobial activity. In addition, the hexane-soluble part, the AcOEt-soluble part, the precipitate and frs. a-f (chromatographed on Diaion HP20 with $\mathrm{H}_{2} \mathrm{O} / \mathrm{MeOH}$ and acetone as the eluents) displayed no activity (Fig. 1). This means that enzymatically hydrolyzed coix extract has only trace or no activity. On RP-18 TLC (solvent system: $\mathrm{MeOH} / \mathrm{H}_{2} \mathrm{O}=9 / 1$ ), UV (254 nm)-absorbent spots were not observed in enzymatically hydrolyzed coix extract, but five to six brown spots were observed after spraying with sulfuric acid $\left(\mathrm{H}_{2} \mathrm{SO}_{4}\right)$ and gentle heating. These spots were thought to be oligosaccharides and/or polysaccharides generated by $\alpha$-amylase in the seed of Coix lachrymajobi.

\section{Structure determinations of peracethylated main constitu-} ents

The structure elucidation of the main constituents in enzymatically hydrolyzed coix extract was carried out after peracetylation. The reaction mixture was subjected to column chromatography on silica gel, affording five compounds $\mathbf{1} \mathbf{a b}, \mathbf{2} \mathbf{a b}, \mathbf{3 a b}, \mathbf{4} \mathbf{a b}$, and $\mathbf{5 a b}$ (Fig. 2).

The ${ }^{1} \mathrm{H}$ - and ${ }^{13} \mathrm{C}-\mathrm{NMR}$ spectra indicated that $\mathbf{1 a b}$ was a mixture of $\alpha$ and $\beta$ isomers of glucose pentaacetate $[\alpha$ anomeric proton: $\delta 6.33(1 \mathrm{H}, \mathrm{d}, J=3.7 \mathrm{~Hz}), \alpha$ anomeric carbon: $\delta 89.1$, and $\beta$ anomeric proton: $\delta 5.72(1 \mathrm{H}, \mathrm{d}, J=$ $8.3 \mathrm{~Hz}$ ), $\beta$ anomeric carbon: $\delta$ 91.7] (Tables 1,2$)$. Ultimately, the identification of $\mathbf{1 a b}$ was carried out by comparisons of $\mathbf{1 a b}$ with standard $\alpha$-D-glucose pentaacetate and $\beta$-D-glucose pentaacetate. The ratio of $\alpha / \beta$ isomers was $1 / 2$, as calculated from the anomeric proton (H-1) signal area of each isomer on ${ }^{1} \mathrm{H}-\mathrm{NMR}$.

Similarly, 2ab, 3ab, $4 \mathbf{a b}$, and $5 \mathbf{a b}$ were also mixtures of $\alpha / \beta(1 / 2)$ isomers of oligosaccharides, which showed two sets of $\alpha / \beta$ anomeric proton (H-1) signals on ${ }^{1} \mathrm{H}$ NMR. The structure determination of $\mathbf{2 a b}, 3 \mathbf{a b}, \mathbf{4 a b}$, and $\mathbf{5 a b}$ was carried out after $\alpha$ isomerization by using $\mathrm{ZnCl}_{2}$ in $\mathrm{Ac}_{2} \mathrm{O}$ (see Materials and Methods section), because it was difficult to determine the structures of the $\alpha / \beta$ isomer mixtures.
Alpha-isomerized 2a was thought to be $\alpha$-diglucopyranose octaacetate, so the assignment of the signals due to two sets of $\alpha$-glucosyl protons $[\delta 5.44(1 \mathrm{H}, \mathrm{d}, J=3.8$ $\left.\left.\mathrm{Hz}, \mathrm{H}-1^{\prime}\right), \delta 6.25(1 \mathrm{H}, \mathrm{d}, J=3.5 \mathrm{~Hz}, \mathrm{H}-1)\right]$ of $2 \mathrm{a}$ was performed by means of ${ }^{1} \mathrm{H}-{ }^{1} \mathrm{H}$ two-dimensional correlation spectroscopy (2D COSY) and HMQC as summarized in Fig. 3. In the HMBC experiment, a correlation was observed between $\delta 5.44\left(\mathrm{H}-1^{\prime}\right)$ and $\delta 72.3$ (C-4). Based on the results, $2 \mathbf{a}$ was formulated as $\alpha$-maltose octaacetate (Fig. 3, Tables 1, 2). The identification of $2 \mathbf{a}$ was carried out by comparison of the spectral data of $\mathbf{2 a}$ with those of synthesized standard $\alpha$-D-maltose octaacetate and $\alpha$-D-maltose octaacetate.

Alpha-isomerized $3 \mathrm{a}$ was thought to be $\alpha$-triglucopyranose undecaacetate, and signals due to three sets of $\alpha$-glucosyl protons $\left[\delta 5.40\left(1 \mathrm{H}, \mathrm{d}, J=4.0 \mathrm{~Hz}, \mathrm{H}-1^{\prime \prime}\right), \delta 5.30\right.$ $\left.\left(1 \mathrm{H}, \mathrm{d}, J=4.1 \mathrm{~Hz}, \mathrm{H}-1^{\prime}\right), \delta 6.22(1 \mathrm{H}, \mathrm{d}, J=3.6 \mathrm{~Hz}, \mathrm{H}-1)\right]$ of 3 a were assigned by means of ${ }^{1} \mathrm{H}-{ }^{1} \mathrm{H}$ COSY and $\mathrm{HMQC}$. In the HMBC experiment, correlations were observed between $\delta 5.30\left(\mathrm{H}-1^{\prime}\right)$ and $\delta 73.3(\mathrm{C}-4)$, and also between $\delta 5.40\left(\mathrm{H}-1^{\prime \prime}\right)$ and $\delta 72.3\left(\mathrm{C}-4^{\prime}\right)$. Based on these results, 3 a was formulated as $\alpha$-maltotriose undecaacetate (Fig. 3, Tables 1,2). The identification of $\mathbf{3 a}$ was carried out by comparison of the spectral data of $\mathbf{3 a}$ with data for a synthesized standard obtained from $\alpha$-maltotriose.

Alpha-isomerized $\mathbf{4 a}$ was thought to be $\alpha$-tetraglucopyranose tetradecaacetate, and signals due to four sets of $\alpha$-glucosyl protons $\left[\delta 5.42\left(1 \mathrm{H}, \mathrm{d}, J=4.3 \mathrm{~Hz}, \mathrm{H}-1^{\prime \prime \prime}\right)\right.$, $\delta 5.29\left(1 \mathrm{H}, \mathrm{d}, J=4.2 \mathrm{~Hz}, \mathrm{H}-1^{\prime \prime}\right), \delta 5.31(1 \mathrm{H}, \mathrm{d}, J=4.1 \mathrm{~Hz}, \mathrm{H}-$ $\left.\left.1^{\prime}\right), \delta 6.25(1 \mathrm{H}, \mathrm{d}, J=3.8 \mathrm{~Hz}, \mathrm{H}-1)\right]$ of $4 \mathrm{a}$ were assigned by means of ${ }^{1} \mathrm{H}^{-1} \mathrm{H}$ COSY and HMQC. In the HMBC experiment, correlations were observed between $\delta 5.31\left(\mathrm{H}-1^{\prime}\right)$ and $\delta 73.3(\mathrm{C}-4)$, and between $\delta 5.29\left(\mathrm{H}-1^{\prime \prime}\right)$ and $\delta 72.3(\mathrm{C}$ $\left.4^{\prime}\right)$, and also between $\delta 5.42\left(\mathrm{H}-1^{\prime \prime \prime}\right)$ and $\delta 73.4\left(\mathrm{C}-4^{\prime \prime}\right)$. Based on these results, $4 \mathbf{a}$ was formulated as $\alpha$-maltotetraose tetradecaacetate (Fig. 3, Tables 1,2). Ultimate$1 \mathrm{y}$, the identification of $\mathbf{4 a}$ was carried out by comparison of the spectral data of $\mathbf{4 a}$ with data for a standard synthesized from maltotetraose.

Alpha-isomerized 5a was thought to be $\alpha$-pentaglucopyranose heptadecaacetate, and signals due to five sets of $\alpha$-glucosyl protons [ $\delta 5.41\left(1 \mathrm{H}, \mathrm{d}, J=4.0 \mathrm{~Hz}, \mathrm{H}-1^{\prime \prime \prime \prime}\right), \delta$ $5.29\left(1 \mathrm{H}, \mathrm{d}, J=4.2 \mathrm{~Hz}, \mathrm{H}-1^{\prime \prime \prime}\right), \delta 5.29(1 \mathrm{H}, \mathrm{d}, J=4.3 \mathrm{~Hz}, \mathrm{H}-$ $\left.1^{\prime \prime}\right), \delta 5.31\left(1 \mathrm{H}, \mathrm{d}, J=3.9 \mathrm{~Hz}, \mathrm{H}-1^{\prime}\right), \delta 6.25(1 \mathrm{H}, \mathrm{d}, J=3.8 \mathrm{~Hz}$, $\mathrm{H}-1)]$ of $5 \mathbf{a}$ were assigned by means of ${ }^{1} \mathrm{H}^{-1} \mathrm{H}$ COSY and HMQC. In the HMBC experiment, correlations were observed between $\delta 5.31\left(\mathrm{H}-1^{\prime}\right)$ and $\delta 73.3(\mathrm{C}-4)$, and between $\delta 5.29\left(\mathrm{H}-1^{\prime \prime}\right)$ and $\delta 72.4\left(\mathrm{C}-4^{\prime}\right)$, and between $\delta$ $5.29\left(\mathrm{H}-1^{\prime \prime \prime}\right)$ and $\delta 73.3\left(\mathrm{C}-4^{\prime \prime}\right)$, and also between $\delta 5.41$ $\left(\mathrm{H}-1^{\prime \prime \prime \prime}\right)$ and $\delta 73.4\left(\mathrm{C}-4^{\prime \prime \prime}\right)$. Based on these results, 5a was formulated as $\alpha$-maltopentaose heptadecaacetate (Fig. 3, Tables 1, 2). The identification of $\mathbf{5 a}$ was carried out by comparison of its spectral data of $5 \mathbf{a}$ with those of a standard synthesized from $\alpha$-maltopentaose.

Thus, the main constituents of enzymatically hydrolyzed coix extract were all oligosaccharides in which several molecules of glucose were $\alpha-(1 \rightarrow 4)$ conjugated. 
a

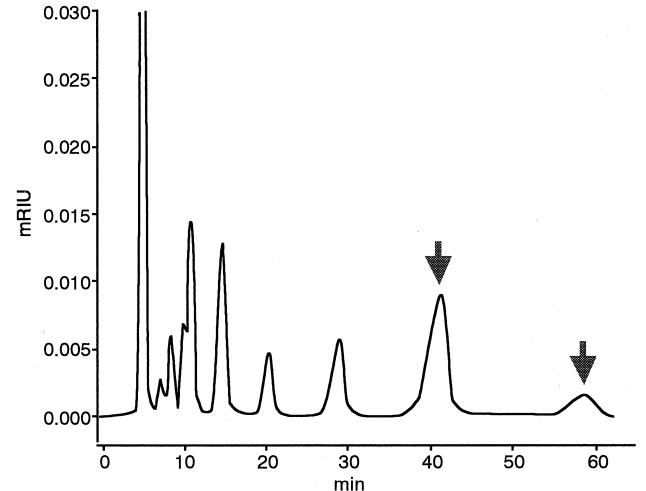

b

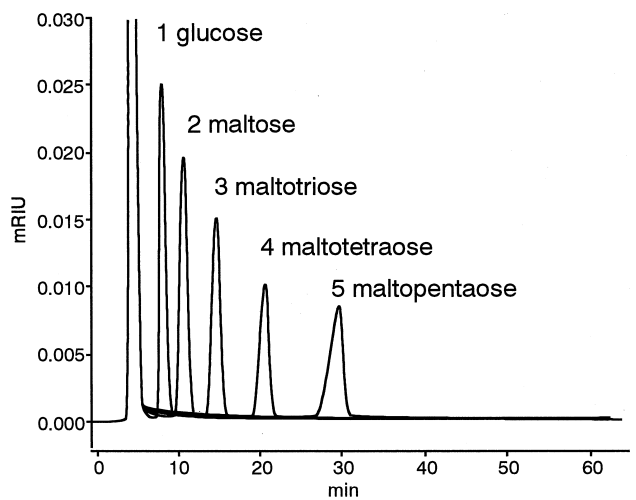

Fig. 4. HPLC profiles of enzymatically hydrolyzed coix extract and standard oligosaccharides (condition A)

a) enzymatically hydrolyzed coix extract, b) standard oligosaccharides (glucose, maltose, maltotriose, maltotetraose, and maltopentaose). The arrows indicate peaks assigned to maltohexaose and maltoheptaose, respectively (see Fig. 5).

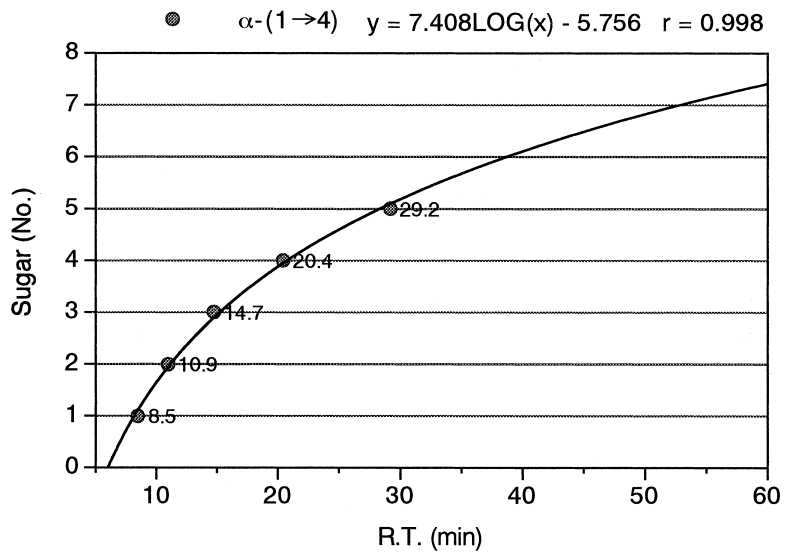

Fig. 5. Relationship between numbers of glucose units of $\alpha-(1 \rightarrow 4)$ conjugated oligosaccharide and the retention times (HPLC condition A)

HPLC analysis of main constituents in enzymatically hydrolyzed coix extract

In Fig. 4a and 4b, HPLC chromatograms (condition A) of enzymatically hydrolyzed coix extract and glucose, maltose, maltotriose, maltotetraose and maltopentaose standards are shown. The retention times of these standards were $8.5 \mathrm{~min}, 10.9 \mathrm{~min}, 14.7 \mathrm{~min}, 20.4 \mathrm{~min}$,
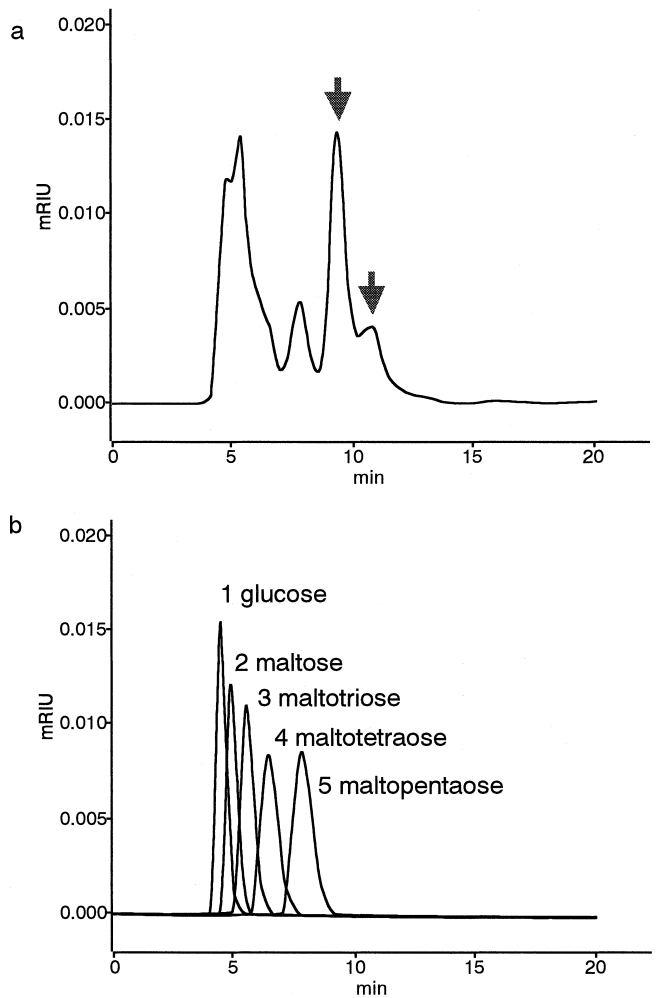

Fig. 6. HPLC profiles of enzymatically hydrolyzed coix extract and standard oligosaccharides (condition B)

a) enzymatically hydrolyzed coix extract, b) standard oligosaccharides (glucose, maltose, maltotriose, maltotetraose, and maltopentaose). The arrows indicate peaks assigned to maltohexaose and maltoheptaose, respectively.

and 29.2 min, respectively, under condition A. The constituents of the coix extract were identified as glucose, maltose, maltotriose, maltotetraose, and maltopentaose by comparison of the retention times with those of the standards. In addition, other peaks at $41.5 \mathrm{~min}$ and 58.0 min were shown to be due to maltohexaose and maltoheptaose, respectively, based on the relationship ( $y=$ 7.408LOG $(x)-5.756$, correlation coefficient $r=0.998$ ) between the number of glucoses of $\alpha-(1 \rightarrow 4)$ conjugated oligosaccharides and the retention times, as shown in Fig. 5. In order to ascertain the existence of polyoligosaccharides with over seven $\alpha$-(1 $\rightarrow 4)$-conjugated glucose residues, this extract was analyzed under HPLC condition B. In Figs. 6a and 6b, HPLC chromatograms (condition B) of enzymatically hydrolyzed coix extract and standard sugars are shown. The marked peaks at $9.6 \mathrm{~min}$ and $11.0 \mathrm{~min}$ were assigned as maltohexaose and maltoheptaose, respectively, but no peak was obtained at longer retention times. In addition, in order to quantify the oligosaccharides, a calibration curve $(y=$ $(1 \mathrm{E}+05) x-(4 \mathrm{E}+04)$, correlation coefficient $r=0.978)$ for peak area against quantity injected was prepared for glucose, maltose, maltotriose, maltotetraose, and maltopentaose within the range of $0.1-10 \mathrm{mg} / \mathrm{mL}$. Since the calibration curves were identical, the calibration curve is applicable to both for maltohexaose and 
Table 3. Concentrations of Sugars in Enzymatically Hydrolyzed Coix Extract

\begin{tabular}{lc}
\hline \hline \multicolumn{1}{c}{ Sugar } & Conc. $(\mathrm{mg} / \mathrm{mL})$ \\
\hline Glucose & 0.8 \\
Maltose & 2.4 \\
Maltotriose & 2.5 \\
Maltotetraose & 1.2 \\
Maltopentaose & 1.9 \\
Maltohexaose & 4.8 \\
Maltoheptaose & 0.4 \\
\hline
\end{tabular}

maltoheptaose. The concentrations of these sugars in enzymatically hydrolyzed coix extract are given in Table 3. Based on these investigations, the main constituents of enzymatically hydrolyzed coix extract are confirmed to be a mixture of oligosaccharides containing one to seven $\alpha-(1 \rightarrow 4)$ conjugated glucose unit.

Antimicrobial substances have been found in Gramineae, such as hordatines $\mathrm{A}, \mathrm{B}^{4)}$ and avenacins $\mathrm{A}, \mathrm{B}^{5), 6)}$ Ishiguro et $a l .^{7)}$ have identified antimicrobial substances in etiolated seedlings of Coix lachryma-jobi L. var. mayuen STAPF as coixinden $\mathrm{A}^{8)}$ (3, 5-dimethoxy-1H-inden-1one) and coixinden $B^{9)}$ (1-acetyl-1-hydroxy-3,5-dimethoxy- $1 H$-indene). However, we could not detect antimicrobial substances in enzymatically hydrolyzed coix extract, used as a natural preservative, despite the careful use of a photodiode array detector to examine the HPLC eluates (data not shown).

As described above, the main components of enzymatically hydrolyzed coix extract were identified as a mixture of oligosaccharides, containing one to seven glucose were $\alpha$-(1 $\rightarrow 4)$-conjugated glucose units, but they showed no antimicrobial activity against 3 kinds of microbes. The main commercial use of the mixture of oligosaccharides in enzymatically hydrolyzed coix extract, is as a coating for strawberries on cakes to retain freshness. Therefore, the preservative effect of this extract may have been caused by the fact that air contact with the surface of the food is blocked by these sugars. It is proposed that the effect of enzymatically hydrolyzed coix extract treatment is primarily to create an air-stable luster on foods.

\section{References}

1) Notice No. 120 (Apr. 16, 1996) List of Existing Food Additives, Ministry of Health and Welfare.

2) Ikekawa, N. ed., "Seirikasseibusshitsu No Bioassei", Tokyo, Kodansha, 1984, p. 227-234.

3) Furuya, T., Matsuura, Y., Mizobata, S., Takahara, S., Takahashi, K., Research for the development of natural antimicrobial materials. I. - Antimicrobial activity and effective constituents in Mosla chinensis Maxim-. Nippon Shokuhin Kagaku Gakkaishi (Jpn. J. Food Chem.), 4, 114-119 (1997).

4) Smith, T. A., Best, G. R., Distribution of the hordatines in barley. Phytochemistry, 17, 1,093-1,098 (1978).

5) Crombie, L., Crombie, W. M. L., Whiting, D. A., Isolation of avenacins A-1, A-2, B-1, and B-2 from oat roots: Structures of their 'aglycones', the avenestergenins. J. Chem. Soc., Chem. Commun., 1984, 244-246.

6) Crombie, W. M. L., Crombie, L., Distribution of avenacins A-1, A-2, B-1 and B-2 in oat roots: Their fungicidal activity towards 'take-all' fungus. Phytochemistry, 25, 2069-2073 (1986).

7) Ishiguro, Y., Okamoto, K., Sakamoto, H., Sonoda, Y., Antimicrobial substances coixindens $\mathrm{A}$ and $\mathrm{B}$ in etiolated seedlings of adlay. Nippon Nogeikagaku Kaishi, 67, 1405-1410 (1993).

8) Ishiguro, Y., Okamoto, K., Sakamoto, H., Sonoda, Y., A novel antimicrobial substance in etiolated seedling of adlay. Biosci. Biotech. Biochem., 57, 866 (1993).

9) Ishiguro, Y., Okamoto, K., Ojima, F., Sonoda, Y., A novel antimicrobial substance in etiolated seeding of adlay. Chem. Lett., 1993, 1139-1140. 